\title{
Expressions of heparanase and upstream stimulatory factor in hepatocellular carcinoma
}

\author{
Bin Chen ${ }^{1}$, Xiao-Peng Chen ${ }^{1 *}$, Ming-Shi Wu' ${ }^{1}$, Wei Cui ${ }^{1}$ and Min Zhong ${ }^{2}$
}

\begin{abstract}
Background: The expression of heparanase (HPSE) was associated with postoperative metastatic recurrence in patients with hepatocellular carcinoma (HCC). The six E-box binding sites in the core promoter of the HPSE gene suggested that transcription factors of E-box such as upstream stimulatory factor (USF) might regulate the transcription of the HPSE gene. The aim of our study is to measure the levels of HPSE and USF expression and investigate the relationship between USF expression and clinicopathological parameters in patients with HCC.

Methods: HPSE, USF1 and USF2 expressions in human HCC cell lines (BEL-7402, HepG2 and HCCLM3) and 15 fresh human HCC tissue samples were measured by real-time reverse transcriptase-PCR and Western blot analysis. The normal liver cell line QSG7701 or fresh normal liver tissue samples obtained from 15 additional surgical patients with hepatic rupture was used as a control. The protein expressions were determined by immunohistochemistry in paraffin-embedded human HCC tissues and corresponding non-neoplastic tumor surrounding tissues (NTST) of 57 patients.
\end{abstract}

Results: HPSE, USF1 and USF2 mRNA expressions were increased in HCC cell lines and HCC tissues compared with normal liver cell line and normal liver tissue. The protein expressions of HPSE, USF1 and USF2 in HCC cell lines and HCC tissues were also increased. Both USF1 and USF2 expressions were positively correlated with HPSE. USF1 and USF2 expressions were increased in patients with liver cirrhosis, worse tissue differentiation, advanced HCC stages and metastatic recurrence.

Conclusions: Increased USF in HCC is associated with HPSE expression. USF might be an important factor in regulating HPSE expression and act as a novel marker of metastatic recurrence of HCC patients.

Keywords: Heparanase, Upstream stimulatory factor, Hepatocellular carcinoma, Recurrence

\section{Background}

Hepatocellular carcinoma (HCC) is one of the most common human malignancies and responsible for approximately $5 \%$ of all cancer-related deaths in the world. Postoperative metastatic recurrence is now known to be the major cause of death of patients with HCC [1-3].

Metastatic recurrence of HCC is a complex and multistep biological process that includes loss of adhesion, migration, invasion and proliferation of cancer cells. Many molecules contribute to this process, and some of these molecules are involved in the mechanical aspects, whereas others modulate regulatory pathways.

\footnotetext{
* Correspondence: drcxp@qq.com

'Department of General Surgery, Affiliated Yijishan Hospital of Wannan Medical College, Wuhu, Anhui Province 241001, China

Full list of author information is available at the end of the article
}

Heparanase (HPSE) is an endo-beta-glucuronidase capable of cleaving heparan sulfate. HPSE plays an important role in extravasation and invasion of tumor cells by cleaving heparan sulfate side chains of heparan sulfate proteoglycans on cell surfaces and in extracellular matrices of basement membrane [4-6]. Previous studies demonstrated that increased HPSE activity has been detected in various tumors and was found to correlate with their metastatic potentials [7-11]. Therefore, HPSE might be a metastatic marker and predict postoperative metastatic recurrence in patients with HCC.

To understand the mechanisms of HPSE up-regulation in tumors, the promoter sequence of HPSE gene was cloned and the transcription factor binding sites (TFBS) were subsequently analyzed. Besides various TFBS such as specificity protein 1 (Sp1), GA-binding protein (GABP)

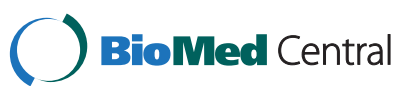

(c) 2014 Chen et al.; licensee BioMed Central Ltd. This is an Open Access article distributed under the terms of the Creative Commons Attribution License (http://creativecommons.org/licenses/by/4.0), which permits unrestricted use, distribution, and reproduction in any medium, provided the original work is properly credited. The Creative Commons Public Domain Dedication waiver (http://creativecommons.org/publicdomain/zero/1.0/) applies to the data made available in this article unless otherwise stated 
and epidermal growth factor-1 (EGR-1) as described in the literatures [12-14], the core promoter included six E-box binding sites which were located at 553-548, 542537, 402-397, 286-281, 34-29 and 14-9 bp upstream of the ATG translation initiation site, respectively [15]. The results suggested that HPSE gene expression might be regulated by E-box sites.

The transcription factor upstream stimulatory factor (USF) was originally identified in HeLa cells by biochemical analysis. Two different genes encode USF which had been defined as USF1 and USF2 [16]. The human cDNA cloning of USF1 and USF2 revealed that the USF belongs to the c-Myc related family of DNA-binding proteins which have a helix-loop-helix motif and a leucine repeat, and that USF interacts with its target DNA sequence (E-box) as a dimer and regulates the transcription of numerous genes [17].

However, the expression of USF1 and USF2 in HCC is unknown. The relationship between USF expression and clinicopathological parameters in patients with HCC remains to be determined. The aims of our study are to measure expression of USF in HCC and evaluate the relationship between USF expression and clinicopathological parameters in patients with HCC.

\section{Methods}

\section{Cell culture}

Human normal liver cell line QSG7701, hepatoma carcinoma cell line BEL-7402 and HepG2 were purchased from Cell Bank (National Academy of Science of China, Shanghai, China). Human highly metastatic liver cancer cell line HCCLM3 was purchased from Liver Cancer Institute (Zhongshan Hospital, Fudan University, Shanghai, China).

QSG7701, BEL-7402, HepG2, and HCCLM3 cells were cultured in DMEM/GlutaMax-1 (Invitrogen, Shanghai, China) supplemented with 10\% FBS (Life Technologies, Carlsbad, CA, USA), $100 \mathrm{IU} / \mathrm{ml}$ penicillin and $100 \mathrm{mg} / \mathrm{ml}$ streptomycin under a $5 \% \mathrm{CO}_{2}$ atmosphere at $37^{\circ} \mathrm{C}$.

\section{Patients and tissue selection}

Fifty-seven patients (44 males and 13 females) underwent primary surgical resection for $\mathrm{HCC}$ in Yijishan Hospital of Wannan Medical College (Anhui province of China) between January 2008 and December 2011. The average age was 55 years (range from 32 to 82 years). None of the patients had received preoperative therapy. All primary HCC tissue samples taken from the 57 patients were fixed in 10\% formalin, embedded in paraffin, sectioned consecutively at $4 \mu \mathrm{m}$ and stained by $\mathrm{H} \& \mathrm{E}$ for immunohistochemical analysis. The diagnoses were confirmed by histopathologic study. Tumor stage was determined according to the 2002 International Union Against Cancer TNM classification system. Tumor differentiation was graded by the Edmondson grading system. The patients were divided into high-tendency to metastatic recurrence group $(\mathrm{n}=35)$ and low-tendency to metastatic recurrence group $(\mathrm{n}=22)$ according to the presence or absence of the cancer emboli, intrahepatic dissemination (satellite foci or multiple nodules), disintegrated tumor capsule and/or lymph node metastasis. The clinicopathological features of these patients are summarized in Table 1.

Fifteen patients were selected randomly from the 57 cases. The fresh tissue samples were immediately frozen in liquid nitrogen and stored at $-80^{\circ} \mathrm{C}$ after hepatectomy for real-time RT-PCR and Western blotting. Non-neoplastic tumor surrounding tissues (NTST) specimens were obtained from tissues at a clear distance from the tumor edge $(>1 \mathrm{~cm})$. The fresh normal liver tissue (NLT) was obtained from 15 additional surgical patients with hepatic rupture.

Written informed consent was obtained from these patients. The research protocol followed the ethical guidelines of the Declaration of Helsinki and was approved by the Ethics Committee of the Yijishan Hospital.

\section{RNA isolation and real-time RT-PCR analysis}

The extraction of total RNA was performed by using Trizol solution (Invitrogen, Shanghai, China) according to the manufacturer's protocols. The RNA was quantified by using UV spectrophotometry at $260 \mathrm{~nm}$. The RNA specimens were stored at $-80^{\circ} \mathrm{C}$ until real-time RT-PCR. Reverse transcription was performed with the Moloney murine leukemia virus (M-MLV) reverse transcriptase (Promega, Beijing, China), using $2 \mu$ g of total RNA and following the manufacturer's instructions. The resulting CDNA was used for real-time quantitative PCR detection. Glyceraldehyde-3-phosphate dehydrogenase (GAPDH) was used as an internal control.

PCR was performed in $25 \mu \mathrm{l}$ of reaction mixture containing $100 \mathrm{ng}$ of both sense and antisense primers (Shanghai Shenggong Company, Shanghai, China), $1 \mu \mathrm{l}$ (200 ng) of the cDNA and $12.5 \mu \mathrm{l}$ SYBR Green PCR Master Mix (QIAGEN SA). The sequences of the primers used for PCR are listed in Table 2. Negative controls (PCR mix without cDNA) were included. The thermal cycle was 10 minutes at $95^{\circ} \mathrm{C}$, and 40 cycles of $95^{\circ} \mathrm{C}$ for 15 seconds, $55^{\circ} \mathrm{C}$ for 30 seconds and $72^{\circ} \mathrm{C}$ for $30 \mathrm{sec}-$ onds. All assays were evaluated using the Stepone plus $^{\text {tw }}$ real-time PCR system (ABI Company, USA), and relative expression was calculated by normalizing the $\mathrm{Ct}$ (threshold cycle) of the target gene to the $\mathrm{Ct}$ of the GAPDH housekeeping gene in the same sample. The experiments, including RNA isolation, reverse transcription and real-time quantitative PCR, were performed in triplicate. 
Table 1 Relationship between heparanase (HPSE), upstream stimulatory factor (USF) expression and tumor characteristics of hepatocellular carcinoma (HCC)

\begin{tabular}{|c|c|c|c|c|c|c|c|c|c|c|}
\hline \multirow[t]{2}{*}{ Features } & \multirow[t]{2}{*}{$\mathbf{n}$} & \multicolumn{3}{|c|}{ HPSE expression } & \multicolumn{3}{|c|}{ USF1 expression } & \multicolumn{3}{|c|}{ USF2 expression } \\
\hline & & + & - & $P$ & + & - & $P$ & + & - & $P$ \\
\hline \multicolumn{11}{|l|}{ Gender } \\
\hline Male & 44 & 31 & 13 & 0.789 & 25 & 19 & 0.850 & 27 & 17 & 0.991 \\
\hline Female & 13 & 8 & 5 & & 7 & 6 & & 8 & 5 & \\
\hline \multicolumn{11}{|l|}{ Age (years) } \\
\hline$<55$ & 39 & 28 & 11 & 0.850 & 22 & 17 & 0.952 & 26 & 13 & 0.230 \\
\hline$\geq 55$ & 18 & 11 & 7 & & 10 & 8 & & 9 & 9 & \\
\hline \multicolumn{11}{|c|}{ Tumor diameter (cm) } \\
\hline$<5$ & 18 & 11 & 7 & 0.419 & 7 & 11 & 0.672 & $8 / 1$ & 10 & 0.520 \\
\hline$\geq 5$ & 39 & 28 & 11 & & 18 & 21 & & 21 & 18 & \\
\hline \multicolumn{11}{|l|}{$\operatorname{AFP}(\mu \mathrm{g} / \mathrm{l})$} \\
\hline$<400$ & 21 & 25 & 11 & 0.709 & 13 & 8 & 0.503 & 12 & 9 & 0.614 \\
\hline$\geq 400$ & 36 & 14 & 7 & & 19 & 17 & & 23 & 13 & \\
\hline \multicolumn{11}{|l|}{ HBsAg } \\
\hline Positive & 41 & 30 & 11 & 0.217 & 20 & 21 & 0.073 & 24 & 17 & 0.477 \\
\hline Negative & 16 & 9 & 7 & & 12 & 4 & & 11 & 5 & \\
\hline \multicolumn{11}{|l|}{ Cirrhosis } \\
\hline Yes & 21 & 13 & 8 & 0.419 & 16 & 5 & 0.020 & 17 & 4 & 0.021 \\
\hline No & 36 & 26 & 10 & & 16 & 20 & & 18 & 18 & \\
\hline \multicolumn{11}{|c|}{ Histological differentiation } \\
\hline Well + moderate & 38 & 22 & 16 & 0.016 & 17 & 21 & 0.014 & 19 & 19 & 0.012 \\
\hline Poor & 19 & 17 & 2 & & 15 & 4 & & 16 & 3 & \\
\hline \multicolumn{11}{|l|}{ TNM staging } \\
\hline $1+\|$ & 31 & 17 & 14 & 0.016 & 12 & 19 & 0.004 & 15 & 16 & 0.028 \\
\hline$I I I+I V$ & 26 & 22 & 4 & & 20 & 6 & & 20 & 6 & \\
\hline \multicolumn{11}{|l|}{ Tendency to MR } \\
\hline High & 35 & 29 & 6 & 0.003 & 24 & 11 & 0.017 & 26 & 9 & 0.012 \\
\hline Low & 22 & 10 & 12 & & 8 & 14 & & 9 & 13 & \\
\hline \multicolumn{11}{|l|}{ Postoperative MR } \\
\hline Yes & 21 & 18 & 3 & 0.032 & 14 & 7 & 0.035 & 16 & 5 & 0.002 \\
\hline No & 30 & 21 & 15 & & 12 & 18 & & 6 & 24 & \\
\hline \multicolumn{11}{|l|}{ HPSE expression } \\
\hline Positive & 39 & & & & 27 & 12 & 0.003 & 28 & 11 & 0.018 \\
\hline Negative & 18 & & & & 5 & 13 & & 7 & 11 & \\
\hline
\end{tabular}

Abbreviations: AFP alpha-fetoprotein, HBsAG hepatitis B surface antigen, MR metastatic recurrence.

\section{Western blot analysis}

Total protein extracts $(50 \mu \mathrm{g})$ were prepared in sample buffer containing $20 \mathrm{mM}$ Tris ( $\mathrm{pH} 8.0), 5 \mathrm{mM}$ ethylenediaminetetraacetic acid (EDTA), $0.5 \%$ Triton X-100 and complete Mini, EDTA-free protease inhibitors (1:25; Roche Diagnostics, Mannheim, Germany).

For Western blot analyses, $50 \mu \mathrm{g}$ of protein were loaded on a $12 \%$ SDS-PAGE gel. The gel was transferred onto a nitrocellulose transfer membrane (Santa Cruz
Biotechnology Inc., Santa Cruz, CA, USA) following separation. Rabbit-anti-HPSE polyclonal antiserum (Jinqiao biotechnology, Beijing, China; at 1:250 dilution), rabbitanti-USF1 polyclonal antiserum (Jinqiao biotechnology, Beijing, China; at 1:250 dilution), rabbit-anti-USF2 polyclonal antiserum (Santa Cruz Biotechnology Inc, Santa Cruz, USA; at 1:250 dilution) or rabbit-anti-GAPDH polyclonal antiserum (Santa Cruz Biotechnology Inc., Santa Cruz, CA, USA; at 1:10,000 dilution) were used as 
Table 2 The sequences of the primers used for PCR

\begin{tabular}{|c|c|c|c|}
\hline Genes & Primers & Sequences & $\begin{array}{l}\text { Size of } \\
\text { product (bp) }\end{array}$ \\
\hline \multirow[t]{2}{*}{ HPSE } & Forward & 5'- GCACAAACACTGACAATCCAAG -3' & 101 \\
\hline & Reverse & 5'- AAAAGGATAGGGTAACCGCAA -3' & \\
\hline \multirow[t]{2}{*}{ USF1 } & Forward & 5'- TTGTCCTGTGCTTGCTTAGAGT -3' & 102 \\
\hline & Reverse & 5'- CAGGGAAAGGAAGAACCAATG -3' & \\
\hline \multirow[t]{2}{*}{ USF2 } & Forward & 5'- AAATTGATGGAACCAGAACACC -3' & 136 \\
\hline & Reverse & 5'- TTGTCTGCGTTACAGTCTGGAAT -3' & \\
\hline \multirow[t]{2}{*}{ GAPDH } & Forward & 5'- GTGGTCTCCTCTGACTTCAACA -3' & 136 \\
\hline & Reverse & 5'- CCACCACCCTGTTGCTGTAG A -3' & \\
\hline
\end{tabular}

primary antibody, respectively. Horseradish peroxidase (HRP)-conjugated anti-rabbit IgG (Maixin biotechnology, Fujian, China) was used as secondary antibody at 1:10,000 dilution. Protein bands were visualized using Chemiluminescence Imaging Systems (Cell Signaling Technology, Danvers, MA, USA). The band intensity was measured using Quantity One software (Bio-Rad Laboratories, Hercules, CA, USA). GAPDH was used as a loading control.

\section{Immunohistochemistry}

The HCC tissue sections of 57 patients were deparaffinized and rehydrated. Then, the sections were boiled in EDTA (1 mmol/l; pH 8.0) for antigen epitope retrieval. Endogenous peroxidase was blocked with $0.3 \%$ hydrogen peroxide. After rinsing, slides were incubated with a mouse polyclonal antibody against HPSE (Jinqiao biotechnology, Beijing, China; at 1:500 dilution), USF1 (Jinqiao biotechnology, Beijing, China; at 1:100 dilution) or USF2 (Santa Cruz Biotechnology Inc., Santa Cruz, USA; at 1:300 dilution) overnight at $4^{\circ} \mathrm{C}$. After washing, the slides were incubated for 30 minutes with HRP-conjugated secondary antibody (Maixin biotechnology, Fujian, China) at room temperature. After this incubation, the slides were washed three times in PBS, and the antibody complexes were colored with diaminobenzidine (DAB) and then counterstained with hematoxylin. The total HPSE and USF immunostaining score was calculated as the sum of the presence of positively stained tumor cells and the staining intensity. Briefly, the percent positive staining was scored as 0 ( $<5 \%$, negative), 1 ( 5 to $25 \%$, sporadic), 2 ( 25 to $50 \%$, focal), 3 ( 50 to $75 \%$, diffuse) or 4 (>75\%, diffuse). The staining intensity was score as 0 (no staining), 1 (weakly stained), 2 (moderately stained) or 3 (strongly stained). Each specimen was evaluated in eight fields at $\times 400$ magnification by two independent pathologists who were unaware of the clinical data. Both percent positivity of cells and staining intensity were decided under double-blind condition. The total immunostaining score was calculated with the value of percent positivity score $\times$ staining intensity score, which ranged from 0 to 12. We defined HPSE, USF1 and USF2 expression levels as follows: - (score 0 to 1$),+$ (score 2 to 3$),++$ (score 4 to 5$)$ and $+++($ score $>5)$. For inconsistent evaluations of individual slides, both observers reviewed the slide again to obtain a consensus. The patients were divided into negative expression group (-) and positive expression group $(+,++$ and +++$)$ according to HPSE or USF expression level.

\section{Follow-up}

All patients were followed up until December 2012. The median follow-up time of patients with HCC was 23 months (range from 12 to 60 months). Recurrence and metastasis were diagnosed by clinical examination, alpha-fetoprotein (AFP) measurement, liver ultrasonography, and computed tomography (CT) scan.

\section{Statistical analysis}

The results of the descriptive analyses of variables were reported as mean \pm standard deviation (SD). Analysis of variance and q-test were used to compare the difference among/between groups. Statistical comparisons for significance between different groups were evaluated by the chi-square test or the Fisher's exact test. Spearman's rank correlation coefficient was used to find the correlation between two sets of data. All statistical analyses were performed using the SPSS 13.0 software package (SPSS Inc., Chicago, IL, USA), and $P<0.05$ was considered statistically significant.

\section{Results}

Expressions of HPSE, USF1 and USF2 in liver cancer cell lines and primary HCC

The mean levels of HPSE, USF1 and USF2 mRNA expression in the three HCC cell lines were significantly higher than those in normal liver cell line QSG7701 $(P<0.05)$. Furthermore, USF2 expression in HCCLM3 was significantly higher than those in BEL-7402 and HepG2 $(P<0.05)$ (Table 3, Figure $1 \mathrm{~A})$. The mean level of HPSE mRNA expression in HCC tumor tissues was significantly increased compared with corresponding NTST and healthy NLT (all $P<0.01$, respectively). USF1 and USF2 were also found to be up-regulated in primary HCC tumor tissues (all $P<0.001$, respectively) (Table 3 , Figure 1B).

The levels of HPSE, USF1 and USF2 protein expression in HCC cell lines were significantly increased (Figure 1C). The HPSE, USF1 and USF2 protein expression levels were all increased in HCC tissues compared with corresponding NTST (Figure 1D). 
Table 3 The relative mRNA expression levels of heparanase (HPSE), upstream stimulatory factor (USF) 1 and USF2 in human hepatocellular carcinoma (HCC) cell lines and HCC tissues

\begin{tabular}{|c|c|c|c|c|c|c|c|}
\hline \multirow[t]{2}{*}{ Genes } & \multicolumn{4}{|l|}{ Cells } & \multicolumn{3}{|l|}{ Tissues } \\
\hline & QSG7701 & BEL-7402 & HepG2 & HCCLM3 & $\overline{\mathrm{NLT}}$ & NTST & $\mathrm{HCC}$ \\
\hline HPSE & $0.11 \pm 0.06^{a}$ & $1.98 \pm 0.13$ & $1.50 \pm 0.14$ & $3.01 \pm 0.65$ & $0.15 \pm 0.08$ & $0.20 \pm 0.09$ & $1.75 \pm 0.55^{c}$ \\
\hline USF1 & $0.11 \pm 0.05^{a}$ & $1.50 \pm 0.12$ & $2.34 \pm 0.32$ & $2.38 \pm 0.23$ & $0.18 \pm 0.08$ & $0.22 \pm 0.07$ & $1.61 \pm 0.45^{c}$ \\
\hline USF2 & $0.10 \pm 0.04^{a}$ & $1.70 \pm 0.14$ & $10.61 \pm 0.92^{b}$ & $16.84 \pm 1.66^{b}$ & $0.12 \pm 0.09$ & $0.14 \pm 0.09$ & $13.92 \pm 1.45^{c}$ \\
\hline
\end{tabular}

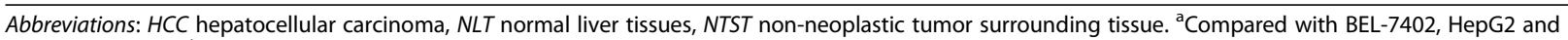
HCCLM3, $P<0.01 ;{ }^{\mathrm{b} C o m p a r e d ~ w i t h ~ B E L-7402, ~} P<0.01 ;{ }^{\mathrm{C}}$ Compared with NLT and NTST, $P<0.01$.

\section{Immunohistochemical staining of HPSE, USF1 and USF2 in} HCC

HPSE and USF1 staining were predominantly in the nuclei, and the positive signal was brown-yellow granules in tumor cell nuclei. HPSE and USF1 expressions in normal hepatocytes of NTST were negative or weakly positive, while mainly moderately or strongly positive in HCC cells (Figure 2A-D). There was a significant difference between the HPSE-positive rate in HCC (39/57) and that in $\operatorname{NTST}(5 / 57, P=0.000)$. USF1-positive rate in $\mathrm{HCC}(32 / 57)$ was significantly higher than that in NTST $(10 / 57, P=0.000)$.

USF2 staining was mainly in the cytoplasm, and the positive signals were yellow or brown granules in the cytoplasm of HCC cells, which were distributed in dots and patches. USF2 expression in normal hepatocytes of NTST was negative, while mainly moderately or strongly positive in HCC cells (Figure 2E and F). There was a significant difference between USF2-positive rate in HCC $(35 / 57)$ and that in NTST $(9 / 57, P=0.000)$.

\section{Relationship between protein expressions and the clinicopathological parameters}

At the time of the last follow-up, 51 patients eventually achieved complete follow-up data (89.5\%). Twenty-one patients were found to have postoperative metastasis or recurrence, and the other 30 were not found to have metastasis or recurrence.

HPSE protein expression was increased significantly in patients with worse tissue differentiation, advanced HCC
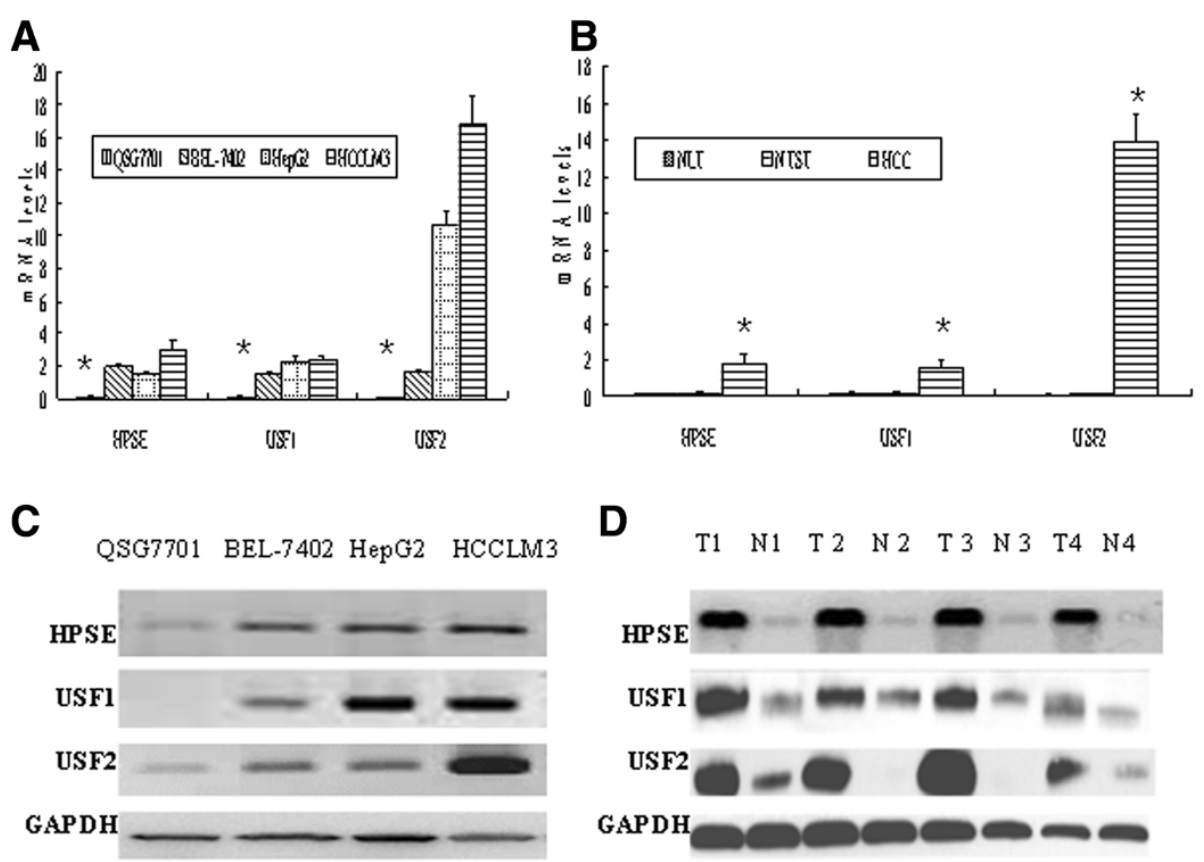

Figure 1 Heparanase (HPSE), upstream stimulatory factor (USF)1 and USF2 mRNA and protein expressions in hepatocellular carcinoma (HCC). HPSE, USF1 and USF2 mRNA and protein expressions were significantly increased in human HCC cell lines and primary HCC surgical specimens assessed with RT-PCR or Western blot. (A) HPSE, USF1 and USF2 mRNA expressions in human HCC cell lines. The normal liver cell line QSG7701 was used as a control. * Compared with BEL-7402, HepG2 and HCCLM3, P<0.01. (B) HPSE, USF1 and USF2 mRNA expression in normal liver tissue, human primary HCC tumor tissues and adjacent non-neoplastic tumor surrounding tissues (NTST) ( $n=15)$. *Compared with NLT and NTST, $P<0.01$. (C) HPSE, USF1 and USF2 protein expressions in human HCC cell lines; (D) HPSE, USF1 and USF2 protein expressions in four representative human primary HCC tumor tissues (T) and adjacent non-tumor liver tissues (N). All experiments were performed three times. 


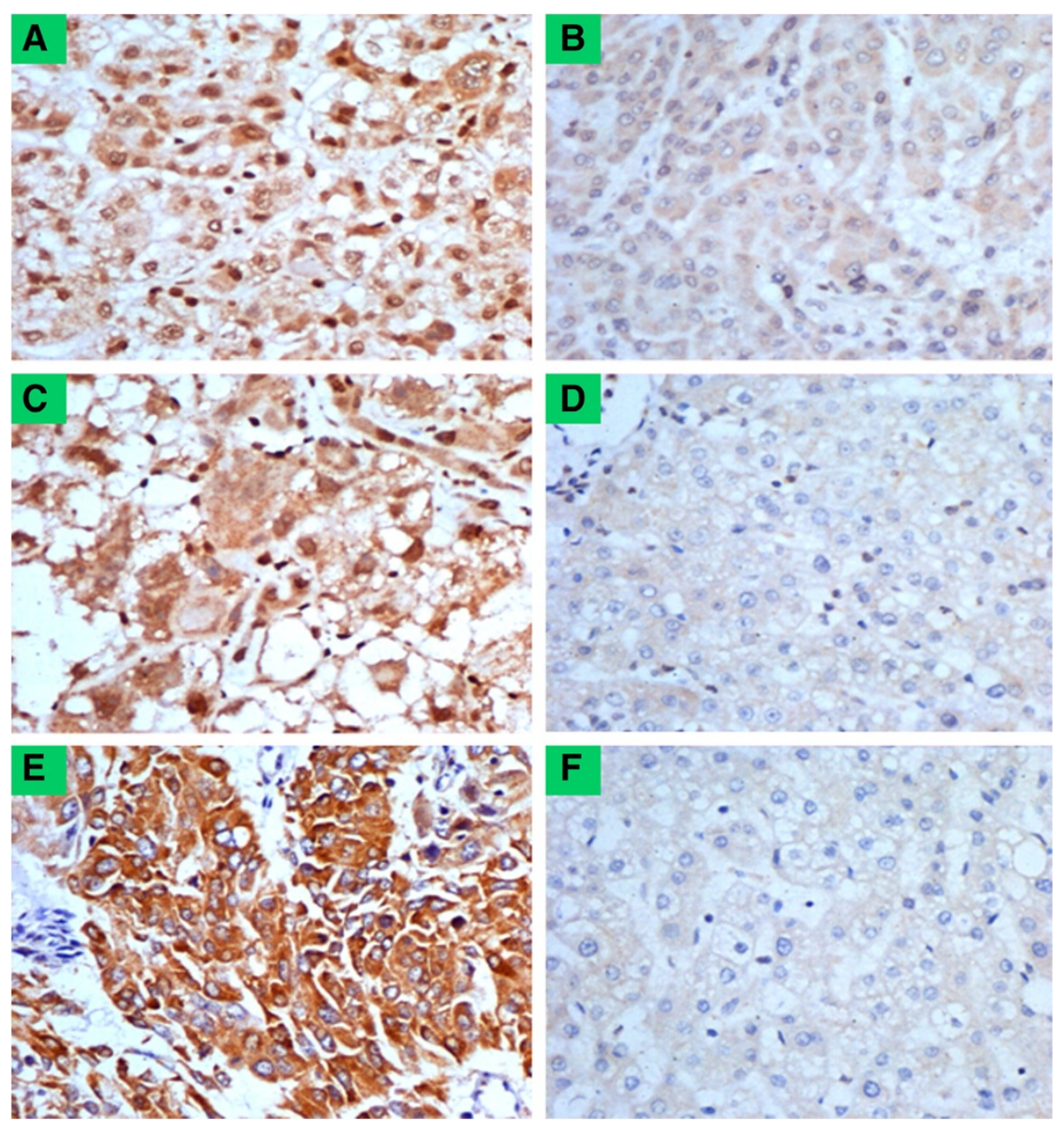

Figure 2 Heparanase (HPSE), upstream stimulatory factor (USF)1 and USF2 protein expression in primary hepatocellular carcinoma (HCC) tissues. HPSE, USF1 and USF2 protein expressions were significantly increased in primary HCC surgical specimens $(n=57)$ detected by immunohistochemistry (original magnification × 400). (A) HPSE-positive expression in HCC tumor tissues. Positive signal of HPSE was brown-yellow granules in nuclei of HCC cells. (B) HPSE weakly positive expression in corresponding non-neoplastic tumor surrounding tissues (NTST).

(C) USF1-positive expression in HCC tumor tissues. Positive signal of USF1 was brown-yellow granules in nuclei of tumor cells. (D) USF1-negative expression in NTST. (E) USF2-positive expression in HCC tumor tissues. Positive signal of USF2 was yellow or brown granules in cytoplasm of HCC cells, which were distributed in dots and patches. (F) USF2-negative expression in NTST. All experiments were performed twice.

stages, high-tendency to metastatic recurrence and postoperative metastatic recurrence. HPSE expression was not associated with sex, age, tumor size, AFP level, hepatitis B surface antigen (HBsAg) status and liver cirrhosis $(P>0.05)$ (Table 1$)$.

USF1 and USF2 protein expressions were significantly increased in patients with liver cirrhosis, worse tissue differentiation, advanced HCC stages, high-tendency to metastatic recurrence and postoperative metastatic recurrence $(P<0.05)$. In addition, patients with positive HPSE expression had higher USF1 and USF2 expressions compared with patients with negative HPSE expression $(P=0.003, P=0.018$, respectively). Both USF1 and USF2 expressions were not associated with sex, age, tumor size, AFP level and HBsAg status $(P<0.05)$ (Table 1$)$.

\section{Correlation between HPSE and USF expression}

To investigate further the correlation of HPSE and USF expression in HCC, Spearman's rank correlation coefficients were calculated. They were $0.344(P=0.009)$ and $0.363(P=0.005)$, respectively (Table 4$)$. It suggested that both USF1 and USF2 expressions were positively correlated with HPSE expression.

\section{Discussion}

High levels of HPSE mRNA and protein are expressed in most malignant tumors including $\mathrm{HCC}$ and are closely associated with tumor metastasis, angiogenesis and other diverse pathological and physiological processes [4-11]. In our previous study, we cloned a 561-bp-long human HPSE gene core promoter and found it contained six 
Table 4 The correlation between heparanase (HPSE) and upstream stimulatory factor (USF) expression in hepatocellular carcinoma (HCC) tissues

\begin{tabular}{|c|c|c|c|c|c|c|c|c|c|c|c|c|}
\hline \multirow[t]{2}{*}{ HPSE } & \multicolumn{4}{|c|}{ USF1 } & \multirow[t]{2}{*}{$r$} & \multirow[t]{2}{*}{$P$} & \multicolumn{4}{|c|}{ USF2 } & \multirow[t]{2}{*}{$r$} & \multirow[t]{2}{*}{$P$} \\
\hline & - & + & ++ & +++ & & & - & + & ++ & +++ & & \\
\hline - & 14 & 2 & 2 & 0 & 0.344 & 0.009 & 15 & 1 & 1 & 1 & 0.363 & 0.005 \\
\hline+ & 2 & 4 & 4 & 3 & & & 2 & 2 & 4 & 4 & & \\
\hline ++ & 5 & 2 & 2 & 6 & & & 3 & 4 & 3 & 5 & & \\
\hline +++ & 4 & 1 & 2 & 4 & & & 2 & 3 & 3 & 4 & & \\
\hline
\end{tabular}

E-box binding sites [15]. As one of the transcription factors of E-box sites, we speculate that transcription of the HPSE gene might be regulated by USF in HCC. USF is a ubiquitously expressed multifunctional transcription factor [16-20], but USF expression and its role in HCC remain unknown $[21,22]$.

In this study, we found the relative expression levels of HPSE and USF were significantly increased in the HCC cell lines and HCC tumor tissues compared with the normal liver cell line or corresponding NTST. These results suggest USF might be a biological indicator of malignant potential of HCC. Highest USF2 expression level was found in HCCLM3 among all three HCC cell lines, and HCCLM3 was a human HCC cell line with high metastatic potential [23]. Therefore, USF2 might be a potential marker of the metastatic recurrence of HCC. Furthermore, we found the up-regulations of USF1 and USF2 mRNA expressions in HCC were incompletely in line with that of HPSE expression. It might be explained that HPSE transcription was functionally regulated by many transcription factors, and USF was only one of the transcription factors [12-15].

In our previous study, we found that high HPSE mRNA expression was associated with worse tissue differentiation, advanced HCC stages, high-tendency to metastatic recurrence and postoperative metastatic recurrence [7]. In this study, we found the same results. Furthermore, we also found that both USF1 and USF2 expressions were significantly increased in patients with liver cirrhosis, poor differentiation, advanced tumor stages, the high-tendency to metastatic recurrence and postoperative metastatic recurrence. The close relationship between USF expression and clinicopathological features predicts that USF might boost carcinogenesis and metastatic tumor recurrence. Interestingly, USF expression, rather than HPSE, is associated with liver cirrhosis. The result suggests that USF could also play some role in the formation or regulation of liver cirrhosis.

Additionally, we found USF1 and USF2 expressions were associated with HPSE expression in HCC, and both USF1 and USF2 expressions were positively correlated with HPSE. These results suggest further HPSE expression in HCC might be regulated by USF. Of course, definite evidence and concrete mechanism remain to be further investigated.

\section{Conclusion}

USF1 and USF2 expressions are significantly increased in HCC and positively correlated with HPSE expression. USF might be an important factor in regulating HPSE expression and act as a novel marker of metastatic recurrence of HCC patients.

\section{Abbreviations}

AFP: alpha-fetoprotein; bp: base pair; CT: computed tomography;

DAB: diaminobenzidine; DMEM: Dulbecco's modified Eagle's medium; EDTA: ethylenediaminetetraacetic acid; EGR-1: epidermal growth factor-1; FBS: fetal bovine serum; GABP: GA-binding protein; HBsAg: hepatitis B surface antigen; HCC: hepatocellular carcinoma; GAPDH: glyceraldehyde-3-phosphate dehydrogenase; H\&E: hematoxylin and eosin; HPSE: heparanase;

HRP: horseradish peroxidase; Ig: immunoglobulin; M-MLV: Moloney murine leukemia virus; NLT: normal liver tissue; NTST: non-neoplastic tumor

surrounding tissues; PCR: polymerase chain reaction; Sp1: specificity protein 1; TFBS: transcription factor binding sites; USF: upstream stimulatory factor.

\section{Competing interests}

The authors declare that they have no competing interests.

\section{Authors' contributions}

$B C$ and $M Z$ carried out the RT-PCR studies and Western blot analysis. XPC conceived of the study, carried out the design and drafted the manuscript, participated in the RT-PCR study and Western blot analysis. WC performed the statistical analysis and helped to draft the manuscript. MSW carried out the immunohistochemical study. All authors read and approved the final manuscript.

\section{Acknowledgements}

We thank Dr. Kong Lv and Dr. Meng-Ying Zhang who provided excellent technical assistance of real-time RT-PCR and Western blot analysis on behalf of Central Laboratory, Affiliated Yijishan Hospital of Wannan Medical College. We thank Dr. Lin-Ming Lu and Dr. Yin-Hua Liu who provided excellent technical assistance of immunohistochemistry analysis on behalf of Department of Pathology, Affiliated Yijishan Hospital of Wannan Medical College. We thank Dr. Gang Feng for his medical writing services on behalf of Department of Clinical Laboratory, Affiliated Yijishan Hospital of Wannan Medical College.

This work was supported by Natural Science Foundation of China (NSFC, Grant Number 81272412) and Natural Science foundation of Anhui province, China (Grant Number 11040606 M181).

\section{Author details}

'Department of General Surgery, Affiliated Yijishan Hospital of Wannan Medical College, Wuhu, Anhui Province 241001, China. ${ }^{2}$ Central Laboratory, Affiliated Yijishan Hospital of Wannan Medical College, Wuhu, Anhui Province 241001, China.

Received: 17 February 2014 Accepted: 6 August 2014 Published: 23 August 2014

\section{References}

1. El-Serag HB: Hepatocellular carcinoma. New Engl J Med 2011, 365:1118-1127.

2. Aravalli RN, Steer CJ, Cressman EN: Molecular mechanisms of hepatocellular carcinoma. Hepatology 2008, 48:2047-2063.

3. El-Serag HB, Rudolph KL: Hepatocellular carcinoma: epidemiology and molecular carcinogenesis. Gastroenterol 2007, 132:2557-2576.

4. Kussie PH, Hulmes JD, Ludwig DL, Patel S, Navarro EC, Seddon AP, Giorgio $N A$, Bohlen P: Cloning and functional expression of a human heparanase gene. Biochem Biophys Res Commun 1999, 261:183-187.

5. Vlodavsky I, Friedmann Y, Elkin M, Aingorn H, Atzmon R, Ishai-Michaeli R, Bitan M, Pappo O, Peretz T, Michal I, Spector L, Pecker I: Mammalian 
heparanase: gene cloning, expression and function in tumor progression and metastasis. Nat Med 1999, 5:793-802.

6. Toyoshima M, Nakajima M: Human heparanase. Purification, characterization, cloning and expression. J Biol Chem 1999, 274:24153-24160.

7. Chen XP, Liu YB, Rui J, Peng SY, Peng CH, Zhou ZY, Shi LH, Shen HW, Xu B: Heparanase mRNA expression and point mutation in hepatocellular carcinoma. World I Gastroenterol 2004, 10:2795-2799.

8. El-Assal ON, Yamanoi A, Ono T, Kohno H, Nagasue N: The clinicopathological significance of heparanase and basic fibroblast growth factor expressions in hepatocellular carcinoma. Clin Cancer Res 2001, 7:1299-1305.

9. Komatsu N, Waki M, Sue M, Tokuda C, Kasaoka T, Nakajima M, Higashi N, Irimura T: Heparanase expression in B16 melanoma cells and peripheral blood neutrophils before and after extravasation detected by novel anti-mouse heparanase monoclonal antibodies. J Immunol Methods 2008, 331:82-93.

10. Tang D, Zhang Q, Zhao S, Wang J, Lu K, Song Y, Zhao L, Kang X, Wang J, Xu S, Tian L: The expression and clinical significance of microRNA-1258 and heparanase in human breast cancer. Clin Biochem 2013, 46:926-932.

11. Xu YY, Zhang Y, Wang ZN, Xue Z, Li J, Yang L, Huimian X: Role of heparanase-1 in gastric carcinoma invasion. Asian Pac J Cancer Prev 2009, 10:151-154.

12. Jiang P, Kumar A, Parrillo JE, Dempsey LA, Platt JL, Prinz RA, Xu X: Cloning and characterization of the human heparanase-1 (HPR1) gene promoter. Role of GA-binding peotein and Sp1 in regulating HPR1 BASAL promoter activity. J Biol Chem 2002, 277:8989-8998.

13. DeMestre AM, Rao S, Hornby JR, Soe-Htwe T, Khachigian LM, Hulett MD: Early growth response gene 1 (EGR1) regulates heparanase gene transcription in tumor cells. J Biol Chem 2005, 280:35136-35147.

14. Rao G, Liu D, Xing M, Tauler J, Prinz RA, Xu X: Induction of heparanase-1 expression by mutant B-Raf kinase: role of GA binding protein in heparanase-1 promoter activation. Neoplasia 2010, 12:946-956.

15. Chen XP, Hu LH, Cui W, Wang D, Wu MS, Luo JS, Zhong M: Activity and tumor specificity of human heparanase gene core promoter. Mol Med Rep 2012, 6:867-871.

16. Sawadogo M: Multiple forms of the human gene-specific transcription factor USF. II. DNA binding properties and transcriptional activity of the purified HeLa USF. J Biol Chem 1988, 263:11994-12001.

17. Gregor PD, Sawadogo M, Roeder RG: The adenovirus major late transcription factor USF is a member of the helix-loop-helix group of regulatory proteins and binds to DNA as a dimer. Genes Dev 1990, 4:1730-1740.

18. Sirito M, Walker S, Lin Q, Kozlowski MT, Klein WH, Sawadogo M: Members of the USF family of helix-loop-helix proteins bind DNA as homo- as well as heterodimers. Gene Expr 1992, 2:231-240.

19. Jung HS, Kim KS, Chung YJ, Chung HK, Min YK, Lee MS, Lee MK, Kim KW, Chung JH: USF inhibits cell proliferation through delay in G2/M phase in FRTL-5 cells. Endocr J 2007, 54:275-285.

20. Ocejo-Garcia M, Baokbah TA, Ashurst HL, Cowlishaw D, Soomro I, Coulson $J M$, Woll PJ: Roles for USF2 in lung cancer proliferation and bronchial carcinogenesis. J Pathol 2005, 206:151-159.

21. van Deursen $D$, van Leeuwen $M$, Vaulont $S$, Jansen $H$, Verhoeven $A J$ : Upstream stimulatory factors 1 and 2 activate the human hepatic lipase promoter via E-box dependent and independent mechanisms. Biochim Biophys Acta 2009, 1791:229-237.

22. Ismail PM, Lu T, Sawadogo M: Loss of USF transcriptional activity in breast cancer cell lines. Oncogene 1999, 18:5582-5591.

23. Yang BW, Liang Y, Xia JL, Sun HC, Wang L, Zhang JB, Tang ZY, Liu KD, Chen J, Xue Q, Chen J, Gao DM, Wu WZ: Biological characteristics of fluorescent protein-expressing human hepatocellular carcinoma xenograft model in nude mice. Eur J Gastroenterol Hepatol 2008, 20:1077-1084.

doi:10.1186/s40001-014-0045-9

Cite this article as: Chen et al.: Expressions of heparanase and upstream stimulatory factor in hepatocellular carcinoma. European Journal of Medical Research 2014 19:45.

\section{Submit your next manuscript to BioMed Central and take full advantage of:}

- Convenient online submission

- Thorough peer review

- No space constraints or color figure charges

- Immediate publication on acceptance

- Inclusion in PubMed, CAS, Scopus and Google Scholar

- Research which is freely available for redistribution

Submit your manuscript at www.biomedcentral.com/submit
C Biomed Central 